\title{
Building sickness syndrome in healthy and unhealthy buildings: an epidemiological and environmental assessment with cluster analysis
}

R McL Niven, A M Fletcher, C A C Pickering, E B Faragher, I N Potter, W B Booth, T J Jones, P D R Potter

\begin{abstract}
Objectives-Building sickness syndrome remains poorly understood. Aetiological factors range from temperature, humidity, and air movement to internal pollutants, dust, lighting, and noise factors. The reported study was designed to investigate whether relations between symptoms of sick building syndrome and measured environmental factors existed within state of the art air conditioned buildings with satisfactory maintenance programmes expected to provide a healthy indoor environment.
\end{abstract}

Methods-Five buildings were studied, three of which were state of the art air conditioned buildings. One was a naturally ventilated control building and one a previously studied and known sick building. A questionnaire was administered to the study population to measure the presence of building related symptoms. This was followed by a detailed environmental survey in identified high and low symptom areas within each building. These areas were compared for their environmental performance.

Results-Two of the air conditioned buildings performed well with a low prevalence of building related symptoms. Both of these buildings out performed the naturally ventilated building for the low number of symptoms and in many of the environmental measures. One building (C), expected to perform well from a design viewpoint had a high prevalence of symptoms and behaved in a similar manner to the known sick building. Environmental indices associated with symptoms varied from building to building. Consistent associations between environmental variables were found for particulates (itchy eyes, dry throat, headache, and lethargy) across all buildings. There were persisting relations between particulates and symptoms (headache, lethargy, and dry skin) even in the building with the lowest level of symptoms and of measured airborne particulates (building B). There were also consistent findings for noise variables with low frequency noise being directly associated with symptoms (stuffy nose, itchy eyes, and dry skin) and higher frequency noise being relatively protective across all buildings.

Conclusions-This is the first epidemiological study of expected state of the art, air conditioned buildings. These buildings can produce an internal environment better than that of naturally ventilated buildings for both reported symptoms and environmental variables. The factors associated with symptoms varied widely across the different buildings studied although consistent associations for symptoms were found with increased exposure to particulates and low frequency noise.

(Occup Environ Med 2000;57:627-634)

Keywords: building sickness syndrome; particulates; low frequency noise

The symptom complex known as building sickness syndrome, is experienced by employees working in office environments. The symptoms experienced are non-specific and predominantly upper respiratory in origin (nasal, eye, and throat) but headache and lethargy, potentially more multifactorial in origin, are also experienced. It is normal in studies of these working environments, to designate a symptom as being compatible with building sickness syndrome only if the complainant experiences a work related pattern with the symptom. ${ }^{1}$

The aetiological factors have been investigated extensively and some factors seem to be consistently related to the development of symptoms. It is experienced more often in air conditioned buildings than naturally ventilated buildings which are usually used as control populations for epidemiological studies. However, naturally ventilated buildings as such are an imperfect control as workers in these environments will also experience work related symptoms compatible with building sickness syndrome.

Factors identified as potential causes include particulate matter, ${ }^{2}$ extremes of thermal comfort ${ }^{3}$ reduced humidity, ${ }^{4}$ insufficient fresh air supply, ${ }^{5}$ excessive air movement, ${ }^{6}$ poor lighting, ${ }^{7}$ microbial contamination, ${ }^{8}$ volatile organic compounds, ${ }^{9}{ }^{10}$ and noise. ${ }^{11}$

Underlying these factors, the efficiency of maintenance and cleaning measures are critical, as small blinded interventional studies have shown. ${ }^{12} 13$

Unfortunately, there are many confounding factors under investigation, including the socioeconomic, ethnic, and sex mix of the population. Psychological factors are relevant in determining the threshold at which people will respond adversely to their environment. However, improving physical factors in the 
environment has been shown to improve reported symptoms as shown by blinded intervention studies and more recently studies of moving entire populations to new working environments. ${ }^{14}$

Most studies to date have concentrated on the aetiological factors within potentially poor quality office environments. The current study was designed to investigate which aetiological factors were still relevant to reported symptoms within state of the art buildings of modern design, where there was expected to be a low prevalence of symptoms associated with building sickness syndrome. The basic design was to compare the difference within and between buildings in measured environmental variables between work areas where symptoms were experienced commonly and where symptoms were uncommon (cluster-control environmental comparison).

The study was a collaborative project between a centre with experience in the epidemiological study of the building sickness syndrome and a specialist agency with experience in the detailed and technical aspects of monitoring environmental conditions.

\section{Methods}

POPULATION

Buildings were initially selected from a possible pool of buildings of known modern design on the basis of providing various common types of air conditioned buildings. Acceptance of the study by owners and management limited the overall selection criteria. However, it was possible ultimately to target and obtain agreement from three modern air conditioned buildings with representative designs. For comparison purposes, one naturally ventilated building and a previously studied and known sick building were included. Buildings $\mathrm{A}, \mathrm{B}$, and $\mathrm{C}$ were approached to represent the modern air conditioned building where attention to design and maintenance, provided the expectation of a high quality internal environment. Building D was identified as a naturally ventilated control building. This was included to act as a comparison for the good quality building with a typical naturally ventilated building. Building E was a control sick building included for direct contrast. Typical of many 1970s mechanically ventilated buildings, it had poor thermal comfort and personal control of the local environment. Unexpectedly, building C did not perform as expected as either a healthy well maintained building from an environmental monitoring view point, or from a symptom rating assessment.

Each building provided employee information, demographic details, occupation codes, and floor plans.

A study population of about 1000 was planned, with equivalent population size across the five buildings. People who spent $<80 \%$ of their work time within their own office space or who had been employed for $<3$ months were excluded. Large surface areas with low population density were avoided because of the cluster design of the study. After this was taken into account, random sampling of work areas and floors was performed to reach about 250 workers per building, with the exception of building C, which had a smaller population.

All those comprising the target population received a letter of information, explanation, and clarification of confidentiality.

ADMINISTERED QUESTIONNAIRE

Those identified in the target population and who were available during the week of the study visit were invited to complete an interviewer led standard questionnaire. The presence of the following building related symptoms were included in the questionnaire: runny nose; stuffy nose; itchy eyes; dry throat; dry skin; lethargy; and headache. The questionnaire has a stem design and positive responders were then asked about the frequency, onset, relation to the working day, and relation to weekends and holidays of each symptom with a positive response. Only symptoms which fulfilled the following criteria were accepted as being a building related symptom: occurring at least during most weeks, which started or got worse since the person started working in the current building, and which improved on rest days. Individual information was obtained for demographic details, smoking habits, subjective assessment of the working environment, and their subjective attitude to their work patterns.

\section{CLUSTER ANALYSIS}

With floor plans of each individual work station, areas with clustering of symptoms and areas where there was an absence or low frequency of symptoms were identified. The threshold (calculated as symptoms per work area), for the assessment of a positive cluster of symptoms and a relative absence of symptoms varied for each building, depending on the overall prevalence of symptoms experienced. The aim was to identify areas with a high prevalence of symptoms-hot spots-and those with a low prevalence of symptoms - cold spots - for direct environmental comparison. To be representative of several workers, only spots with a relatively high worker concentration were included. Six hot and six cold spots were then coded in each building and identified as sites for detailed environmental assessment. Environmental assessments were performed within 1 month of the questionnaire study and performed by the environmental assessment team blind to the hot or cold nature of each site until sampling in all buildings was complete and the analysis was performed. The cluster areas identified represent about one third of the total population studied $(n=308)$, only these people are included in the statistical analysis. The number, location, and frequency of measures taken within each cluster area varied for each environmental variable and was decided by the research engineers on the basis of requirement, repeatability and practicality. All site numbers were tagged with the nearest seat location for later reference. Each person within the cluster was then tagged with their own environmental exposure variable for each of the 118 measurements as well as a code value to 
represent their rough proximity to the site of sampling.

ENVIRONMENTAL STUDY

Thermal air movement and thermal comfort

measures

Room air movements - DISA (Dantec, six omnidirectional anemometers) with integral temperature sensors were mounted on a mobile stand at regular intervals at heights between $0.3 \mathrm{~m}$ and $1.8 \mathrm{~m}$. Information gathered included air velocity, air diffusion performance index, dry bulb temperatures, globe temperature, and radiant temperature. Globe temperature and radiant temperature were measured from a black globe.

Purpose built thermal comfort analysers were also used to measure thermal comfort according to procedures laid out in International Standards Organisation (ISO) standard 7730-1984. Measurements were made at $1.1 \mathrm{~m}$ height (head level for a sedentary person). Equipment basically included dry bulb temperature and relative humidity sensors, black globe temperature sensor, omnidirectional air velocity sensor with temperature compensation, and net radiometers to measure asymmetric thermal radiation fields to derive the asymmetric temperature in three orthogonal planes. Readings were taken every 7 minutes by data loggers.

Temperature and air relative humidity $(\mathrm{RH})$ monitors were used to collect a 10 day period of measurements. Squirrel data loggers were connected to relative humidity and dry bulb temperature probes. Dry bulb accuracy of $0.2^{\circ} \mathrm{C}$ and relative humidity of $\pm 5 \%$ were achieved with this system.

\section{Respirable particles}

Mass concentrations of respirable particles were measured with a particle fractionating sampler and a 2 minute sampling period at each site.

Particle counts were performed with a Climet CI-8060 particle counter. Particles were sized in six ranges: $0.3-0.5,0.5-0.7,0.7-$ $1.0,1.0-5.0,5.0-10.0$, and $>10.0 \mu \mathrm{m}$. Sample flow rate was $0.12 \mathrm{l} / \mathrm{s}$ at $1.0 \mathrm{~m}$ height from floor level. A dilution system allowed particle counts up to $7 \times 10^{9}$ to be measured.

\section{Noise variables}

A Bruel and Kjaer type 2231 modular precision sound level meter was used with a semiautomatic data acquisition module. Third octave band sound pressure levels and A weighted (LEQ noise equivalent pressure level) sound power levels were measured. Six repeat measures were taken automatically and remotely at each site over a period of 25 minutes.

Background levels of noise with the building unoccupied were also measured by repeating the measurement programme during the evening with the air conditioning plant (where appropriate) still operational.

\section{Lighting}

Illuminance was measured at the identified sites. Luminance measures of multiple objects within the target area were also taken. All measures were made with a Hagner photometer.

Non-particulate environmental measures Carbon dioxide concentrations were measured at intervals throughout the day at the designated sites. The instrument range used was 0-3000 ppm. The analyser was calibrated before each sample site and each recording was made over a 90 second period. Carbon dioxide concentrations can be used to assess whether quantities of fresh air supply are adequate as $\mathrm{CO}_{2}$ is a human bioeffluent. Inadequate clearance of $\mathrm{CO}_{2}$ indicates insufficient ventilation for the numbers of people working within that space at the time of the measurement.

A second cell also recorded CO concentrations. Raised $\mathrm{CO}$ concentrations are usually indicative of exposure to tobacco smoke, but may also be related to gas and oil fired burner and car engine emissions.

Atmospheric ions (positive and negative) were measured at all locations with a Medion ion analyser type 134B. Four ranges of exposure were measured as a semiquantitative measure of ion exposure: $<1000,1000-5000$, 5000-50 000, and $50000-250000$ ions $/ \mathrm{cm}^{3}$.

Formaldehyde concentrations were measured at the targeted locations and measurements that exceeded the World Health Organisation (WHO) concentration $(0.06 \mathrm{mg} /$ $\mathrm{m}^{3}$ ) were of limited concern. Control samples were also analysed. Increased concentration of formaldehyde above the detection level of the system was only found in building $\mathrm{E}$.

Total organic carbon concentrations were measured with charcoal tubes and active sampling for an 8 hour period. Control samples were again used. Overall $n$-hexane was identified as the most representative compound in each sample and subsequently all results have been calculated as the proportion of carbon in $\mathrm{n}$-hexane. Samples were only taken in buildings C, D, and E.

ANALYSIS

Initially univariate analysis compared each individual exposure variable for symptomatic compared with asymptomatic workers for each symptom in each building separately. Also, the exercise was repeated with all building data linked together. There are several limitations in comparing environmental data from all the buildings together. The relations between exposures and symptoms may not be a linear one. For example, temperature will produce discomfort for workers at extremes above and below those values of accepted comfort. Consequently a U shaped exposure-response relation is likely to exist and lumping buildings together for analysis, may result in false negative associations with different buildings performing at the lower and upper end of the spectrum for that variable. Also, it is likely that the individual causative factors and interactions between causative factors differ within individual buildings and combining data was likely to lose important findings within specific buildings. Separate combined analysis was performed to identify any factors that showed a 
Table 1 Features of the five buildings used in the study

\begin{tabular}{|c|c|c|c|c|c|}
\hline & \multicolumn{5}{|l|}{ Building } \\
\hline & $A$ & $B$ & $C$ & $D$ & $E$ \\
\hline Age $(y)$ & 10 & 4 & 2 & 18 & 20 \\
\hline Population & 1200 & 600 & 250 & 600 & 500 \\
\hline Male (\%) & 60 & 50 & 50 & 60 & 40 \\
\hline Clerical (\%) & 80 & 60 & 50 & 80 & 60 \\
\hline Professional (\%) & 10 & 30 & 40 & 5 & 20 \\
\hline Heating & Yes & Yes & Yes & Yes & Yes \\
\hline Cooling & Wet tower & Wet tower & Wet tower & No & Yes \\
\hline Humidification & Yes & No & Yes & No & No \\
\hline Enthalpy controller & Yes & Yes & No & NA & No \\
\hline Air supply & Linear slot perimeter & Wall mounted floor extract & Ceiling constant volume & Natural & Wall mounted: central extract \\
\hline Windows & Non-openable integral blinds & Openable blinds & Non-openable blinds & Openable & Non-openable blinds \\
\hline Lighting & Flush ceiling & No ceiling & Flush ceiling & Flush ceiling & Suspended low frequency \\
\hline Diffusers & Yes & NA & Yes & Yes & Yes \\
\hline Uplighting & None & $100 \%$ & None & None & None \\
\hline VDU use (\%) & $>80$ & $40-50$ & 60 & 90 & $80-90$ \\
\hline Smoking policy & No smoking & No smoking & Permitted & Restricted & No smoking \\
\hline
\end{tabular}

$\mathrm{NA}=$ not appropriate; lighting=high frequency unless stated; smoking policy=no smoking (complete smoking restriction from ventilated areas); permitted=allowed at discretion of local occupants consent; restricted=restricted areas.

strong linear relation between environmental exposure and variable.

Because of the multiple exposure categories ( $>100$ in all), seven sick building symptoms (already described) and six building codes (buildings A-E separately and data pooled from all buildings), almost 4000 tests of significance were performed. If a 5\% significance level had been accepted then 200 positive associations may have occurred by chance. Consequently, a $0.1 \%(\mathrm{p}<0.001)$ level of significance was used to interpret the findings of univariate analysis.

A multiple logistic regression technique was performed for each building, with symptom as the dependent variable and exposure indices as the independent predictors. Because of the large number of measured variables, regression analyses were performed in stages with environmental grouping of data-for example, all thermal and humidity measurements in one model, noise data in one model, etc. A $1 \%(p<0.01)$ level of significance was used at this stage.

A logistic regression model linking all environmental subgroups together, was not performed as the number of symptomatic people was insufficient and the number of possible implicated causative factors too large to support such an analysis. Also it is likely that the relations between exposure and effect may vary between buildings depending on the mix of environmental factors in any building.

\section{Results}

DESCRIPTIONS OF BUILDINGS

Table 1 summarises the features of the five buildings incorporated in the study. Buildings
A and B represented the expected healthy buildings. There was no significant difference in the clerical or sex distribution of workers to explain a reduced prevalence of symptoms (previous studies have shown that symptoms are more prevalent among female and clerical workers than their male and professional or managerial colleagues). Buildings $\mathrm{A}, \mathrm{B}$, and $\mathrm{E}$ unlike $\mathrm{C}$ and $\mathrm{D}$ enforced formal no smoking policies at the time of the study.

Table 2 summarises the demographic features of the target and study populations within the five building groups. Response rate was about $80 \%$ of the target population and over $95 \%$ of the available target population (not on holiday, on a course, or off sick during the week of the study) with the exception of building $\mathrm{C}$ $(87 \%)$.

Table 3 presents the individual symptom prevalence by building and in all buildings. The data are presented for both the total study population and for the subpopulation subject to the cluster analysis. Generally the prevalence of symptoms was similar in the total study population to that in the cluster analysis subpopulation. There were a few exceptions to this with overrepresentation of symptoms in the analysis population for stuffy nose or runny nose building $\mathrm{A}$, headache building $\mathrm{B}$, and lethargy building E. Buildings $\mathrm{A}$ and $\mathrm{B}$ had the lowest level of individual reported symptoms for all symptoms except dry throat where the naturally ventilated building (D) had the lowest level of symptoms. Building $\mathrm{C}$ had the highest level of reported symptoms except for runny nose in which building D had the highest level,

Table 2 Demographic features of the study population per building

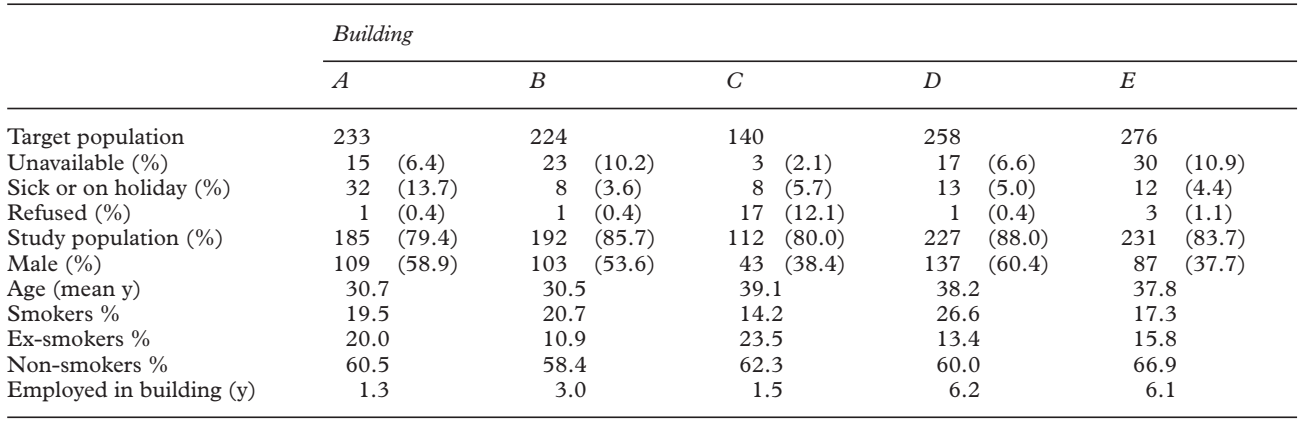


although reported symptoms of runny nose were low overall.

ENVIRONMENTAL CONDITIONS

Detailed description of the measured environmental variables will be the subject of a separate publication. Here we describe a limited number of findings, particularly those that related to symptoms.

\section{Particulates}

Particulates were measured as mass and particle numbers and were selected by size. Total particles were significantly lower in building $B$ at $1.6 \times 10^{7}$ compared with building $\mathrm{A} 1 \times 10^{8}$ and buildings $\mathrm{C}, \mathrm{D}$, and $\mathrm{E} 1.3 \times 10^{8}$. The difference was greatest for the small particulates (0.3-0.5 $\mu \mathrm{m}$ size) compared with the larger particulates $(>10 \mu \mathrm{m})$. Indeed building A had fewer larger particulates and the lowest relative mass of particulates.

Air temperature, humidity, and velocity

Mean air temperature was similar in all five buildings, varying between $23.4^{\circ} \mathrm{C}$ (building C) and $24.1^{\circ} \mathrm{C}$ (building E). The naturally ventilated building had the widest temperature range $\left(21.3^{\circ} \mathrm{C}-28^{\circ} \mathrm{C}\right)$ and building $\mathrm{B}$ the narrowest $\left(22.3^{\circ} \mathrm{C}-25.8^{\circ} \mathrm{C}\right)$. Day time humidity was lowest in building $\mathrm{D}$ (naturally ventilated) at $30 \%-48 \%$ and building $\mathrm{E} 35 \%-$ $45 \%$. Building A had variable humidity both within the workspace and varying by day between $30 \%$ and $60 \%$. Tight humidity control between $40 \%-50 \%$ was achieved in buildings B and $\mathrm{C}$. Air velocity was low in buildings $\mathrm{D}, \mathrm{E}$, and $\mathrm{C}$ at $0.062,0.071$, and $0.080 \mathrm{~m} / \mathrm{s}$, respectively), but was higher in buildings $\mathrm{A}$ and $\mathrm{B}$ $(0.099$ and $0.133 \mathrm{~m} / \mathrm{s})$.

Noise

Multiple noise measures were taken. As an example the LEQ noise equivalent (A

Table 3 Individual symptom prevalence as experienced by building in the target population involving selected high and low symptom reporting areas

\begin{tabular}{|c|c|c|c|c|c|c|}
\hline & \multicolumn{5}{|c|}{ Building } & \multirow[b]{2}{*}{ All } \\
\hline & $A$ & $B$ & $C$ & $D$ & $E$ & \\
\hline \multicolumn{7}{|l|}{ Stuffy nose (\%): } \\
\hline Total population & 11.4 & 11.5 & 34.8 & 15.4 & 15.4 & \\
\hline Analysed population & 20.4 & 10.4 & 35.8 & 9.7 & 19.4 & 18.2 \\
\hline \multicolumn{7}{|l|}{ Runny nose (\%): } \\
\hline Total population & 2.7 & 2.9 & 8.0 & 8.9 & 6.1 & \\
\hline Analysed population & 7.4 & 3.9 & 9.4 & 6.5 & 11.3 & 7.5 \\
\hline \multicolumn{7}{|l|}{ Itchy eyes $(\%)$ : } \\
\hline Total population & 7.5 & 6.8 & 31.2 & 16.7 & 15.2 & \\
\hline Analysed population & 7.4 & 9.1 & 28.3 & 11.3 & 22.6 & 15.3 \\
\hline \multicolumn{7}{|l|}{ Dry throat (\%): } \\
\hline Total population & 7.2 & 8.6 & 31.3 & 4.8 & 23.4 & \\
\hline Analysed population & 11.1 & 10.4 & 26.4 & 4.8 & 25.8 & 15.3 \\
\hline \multicolumn{7}{|l|}{ Headaches (\%): } \\
\hline Total population & 14.1 & 16.7 & 28.5 & 14.1 & 16.7 & \\
\hline Analysed population & 14.8 & 24.7 & 30.2 & 14.5 & 24.2 & 21.8 \\
\hline \multicolumn{7}{|l|}{ Lethargy $(\%)$ : } \\
\hline Total population & 8.3 & 11.5 & 33.0 & 14.1 & 16.7 & \\
\hline Analysed population & 7.4 & 13.0 & 37.7 & 14.5 & 27.4 & 19.5 \\
\hline \multicolumn{7}{|l|}{ Dry skin $(\%):$} \\
\hline Total population & 5.6 & 5.7 & 12.5 & 7.5 & 8.7 & \\
\hline Analysed population & 1.9 & 6.5 & 11.3 & 11.3 & 6.5 & 7.5 \\
\hline \multicolumn{7}{|l|}{ Sample size: } \\
\hline Total population & 185 & 192 & 112 & 227 & 231 & \\
\hline Analysed population & 54 & 77 & 53 & 62 & 62 & 308 \\
\hline
\end{tabular}

Total population=prevalence of symptoms in all those seen as part of overall survey; analysed population=prevalence of symptoms in the those workers, working within the work areas, identified for the cluster analysis and subsequent environmental survey. weighted) was lowest in building $\mathrm{B}$ at $40 \mathrm{dBa}$, $51 \mathrm{dBa}$ in building $\mathrm{A}, 53 \mathrm{dBa}$ in building $\mathrm{E}, 61$ $\mathrm{dBa}$ in building $\mathrm{C}$, and loudest in the naturally ventilated building $\mathrm{D}$. However the low frequency measures (for example, $63 \mathrm{~Hz}$ maximum peak level) was highest in building $\mathrm{E}$ at $74 \mathrm{~dB}$, and lowest in building $\mathrm{B}$ at $40 \mathrm{~dB}$ and building $\mathrm{D}$ at $42 \mathrm{~dB}$.

\section{Ions}

Ions were evenly distributed in the 200-300 ions $/ \mathrm{ml}$ range with a slight predominance of positive ions measured. Building $\mathrm{B}$, however, had more ions overall at 400-800 ions $/ \mathrm{ml}$.

\section{Carbon dioxide}

Carbon dioxide as a marker of fresh air delivery was lowest in buildings A and B at $400-800$ ppm. Buildings $C$ and $E$ ranged from 500$1000 \mathrm{ppm}$, but highest values were measured in building $\mathrm{D}$ at between 1000 and $2600 \mathrm{ppm}$.

UNIVARIATE ANALYSIS OF SYMPTOMS WITH

ENVIRONMENTAL MEASURES

In total, 118 different environmental variables were analysed against seven different symptom variables in five buildings independently and again in buildings overall. This represents about 5000 tests of significance.

It is impossible to present all these data, and the analysis was used to screen out unimportant measures which would not be included in the multiple regression models. However, throughout the univariate analysis, despite using a threshold for significance of $0.1 \%$ $(p<0.001)$, there was a consistent positive relation in each building and in buildings overall, between reported symptoms and particulates (strongest for the larger particle sizes $(>10$ $\mu \mathrm{m})$ ) and for noise variables. For the noise it seemed that low frequency noise was positively associated with symptoms (more noise, more symptoms), however, the higher frequency noise measures showed a negative relation (high frequency noise protective of symptoms).

MUTIVARIATE ANALYSIS OF SYMPTOMS AND ENVIRONMENTAL MEASURES

The effects of environmental measures were analysed individually for each building in subgroups. Only the factors which were identified as having a significant predictive effect on the regression model using the $99 \%$ confidence interval $(\mathrm{p}<0.01)$ are presented. This has been done separately for each building in tables 4-8. A similar set of regression models was performed with the data from all five buildings pooled together (table 9).

Buildings A and B, which are the state of the art buildings with good performance, have few factors significantly related to symptoms. Despite both these buildings performing well, the factors responsible were different when the two buildings were compared. In building A, horizontal asymmetric temperature was related to both dry throat and lethargy. In building B, areas with lower relative humidity had higher reports of itchy eyes and headache, whereas particulate exposure related to headaches, lethargy, and dry skin. These two buildings 
Table 4 Factors predictive of symptoms in building $A$

\begin{tabular}{lll}
\hline Symptom & Environmental factor & $p$ Value \\
\hline $\begin{array}{l}\text { Stuffy nose } \\
\text { Runny nose }\end{array}$ & Reduced noise LEQ maximum & $<0.001$ \\
$\begin{array}{l}\text { Itchy eyes } \\
\text { Dry throat }\end{array}$ & Horizontal assymetric radiant temperature & $<0.01$ \\
$\begin{array}{l}\text { Headhargy } \\
\text { Dry skin }\end{array}$ & Horizontal asymmetric radiant temperature & $<0.01$ \\
\hline
\end{tabular}

Table 5 Factors predictive of symptoms in building $B$

\begin{tabular}{lll}
\hline Symptom & Environmental factor & $p$ Value \\
\hline $\begin{array}{l}\text { Stuffy nose } \\
\text { Runny nose }\end{array}$ & & \\
Itchy eyes & Reduced relative humidity & $<0.01$ \\
Dry throat & Particulates $(0.3-0.5 \mu \mathrm{m})$ & $<0.001$ \\
Headache & Reduced relative humidity & $<0.001$ \\
& Particulates $(10 \mu \mathrm{m})$ & $<0.01$ \\
Lethargy & Particulates $(3-5 \mu \mathrm{m})$ & $<0.001$ \\
Dry skin & & \\
\hline
\end{tabular}

outperform the naturally ventilated building (D) in both reported symptoms and certain measures of environmental comfort. Indeed it was the measures of thermal comfort that seemed to influence symptoms in building $\mathrm{D}$. Increased temperatures, temperature gradients, and reduced thermal comfort indices were predictive of several symptoms. Building D had high concentrations of particulates, although these were only independently related to symptoms at the 0.01 level of significance for dry skin.

Building $\mathrm{C}$ was expected to perform as a state of the art air conditioned building, but had a very high level of reported symptoms, and on the basis of the environmental monitoring performed less well than buildings $\mathrm{A}$ and $\mathrm{B}$. The relation between the measured environmental variables and symptoms has been undermined, as maintenance had been inadvertently carried out between the assessment of symptoms and the environmental study. However, increased temperatures, reduced relative humidity (even though building $\mathrm{C}$ was the best building for relative humidity control), and thermal index measures were predictive of symptoms. Increased particulate concentrations related to stuffy nose, lethargy, and dry skin. Carbon dioxide concentrations were indicative of poor ventilation or excessive recirculation of air, were related to lethargy, and were higher in this building than the other air conditioned building.

Table 6 Factors predictive of symptoms in building $C$

\begin{tabular}{lll}
\hline Symptom & Environmental factor & p Value \\
\hline Stuffy nose & Reduced relative humidity & $<0.01$ \\
Runny nose & Particulates $(1-5 \mu \mathrm{m})$ & $<0.001$ \\
Itchy eyes & Increased temperature (dry bulb) & $<0.01$ \\
& Reduced high frequency noise & $<0.001$ \\
Dry throat & Lower diurnal temperature variation & $<0.01$ \\
Headache & Floor to ankle temperature gradient & $<0.001$ \\
Lethargy & Horizontal asymmetric radiant temperature & $<0.01$ \\
& Dry bulb temperature & $<0.001$ \\
& Increased CO concentrations & $<0.001$ \\
& Particulates (10 $\mu$ m) & $<0.01$ \\
Dry skin & Floor to ankle temperature gradient & $=0.01$ \\
& Globe temperature & $<0.001$ \\
& Horizontal asymmetric radiant temperature & $<0.01$ \\
& Increased low frequency noise & $<0.01$ \\
& Particulates (total count) & $<0.01$ \\
\hline
\end{tabular}

Table 7 Factors predictive of symptoms in building D: the naturally ventilated building

\begin{tabular}{|c|c|c|}
\hline Symptom & Environmental factor & $p$ Value \\
\hline \multicolumn{3}{|l|}{ Stuffy nose } \\
\hline Runny nose & Thermal comfort index (PPD) & $<0.01$ \\
\hline \multirow[t]{2}{*}{ Itchy eyes } & Head floor temperature gradient & $<0.001$ \\
\hline & Mean temperature & $<0.001$ \\
\hline \multicolumn{3}{|l|}{ Dry throat } \\
\hline \multirow[t]{4}{*}{ Headache } & Air diffusion index (ADPI) & $=0.01$ \\
\hline & Air turbulence & $<0.001$ \\
\hline & Mean temperature & $<0.01$ \\
\hline & Reduced high frequency noise & $<0.01$ \\
\hline $\begin{array}{l}\text { Lethargy } \\
\text { Dry skin }\end{array}$ & Particulates $(10 \mu \mathrm{m})$ & $=0.01$ \\
\hline
\end{tabular}

Building E, which was known to be significantly effected by the sick building syndrome, was shown to have the worst environment as measured by various indices It had the highest level of symptoms and many significant relations were identified. Particulates were predictive of all symptoms except dry skin (building $\mathrm{E}$ had the highest concentrations of measured particulates overall). Air velocity, measures of turbulence, thermal comfort, and temperature gradients were all predictive of symptoms.

In the analysis of all building data pooled together there was a paucity of positive relations compared with the individual buildings. However, particulates and noise meas-

Table 8 Factors predictive of symptoms in building $E$

\begin{tabular}{lll}
\hline Symptom & Environmental factor & p Value \\
\hline Stuffy nose & Reduced high frequency noise & $<0.001$ \\
& Increased low frequency noise & $=0.01$ \\
Runny nose & Particulates $(10 \mu \mathrm{m})$ & $<0.001$ \\
& Air velocity & $<0.01$ \\
& Air turbulence & $<0.001$ \\
& Radiant temperature & $=0.01$ \\
& Increased low frequency noise & $=0.001$ \\
& Reduced negative ions & $<0.001$ \\
& Particulates $(0.3-0.5 \mu \mathrm{m})$ & $<0.001$ \\
Itchy eyes & Thermal comfort index & $<0.01$ \\
& Dry bulb temperature & $<0.01$ \\
& Particulates $(10 \mu \mathrm{m})$ & $<0.01$ \\
Dry throat & Floor to ankle temperature gradient & $<0.01$ \\
& Radient temperature & $=0.01$ \\
& Increased CO ${ }_{2}$ concentrations & $=0.01$ \\
& Reduced negative ions & $<0.01$ \\
& Particulates $(10 \mu \mathrm{m})$ & $<0.01$ \\
Headache & Thermal comfort index (PPD) & $<0.01$ \\
& Reduced dry bulb temperature & $<0.01$ \\
& Increased low frequency noise & $<0.01$ \\
& Reduced negative ions & $=0.01$ \\
& Particulates $(10 \mu \mathrm{m})$ & $<0.001$ \\
Lethargy & Reduced high frequency noise & $<0.01$ \\
& Increased low frequency noise & $=0.01$ \\
& Particulates $(5-10 \mu \mathrm{m})$ & $=0.01$ \\
Dry skin & Radiant temperature & $<0.01$ \\
& Increased background noise & $<0.01$ \\
& & \\
& & \\
& &
\end{tabular}

Table 9 Factors predictive of symptoms using pooled data from all five buildings

\begin{tabular}{lll}
\hline Symptom & Environmental factor & $p$ Value \\
\hline Stuffy nose & Reduced high frequency noise & $<0.01$ \\
& Increased low frequency noise & $<0.01$ \\
Runny nose & Air turbulence & $<0.01$ \\
Itchy eyes & Temperature gradient (head floor) & $<0.01$ \\
& Increased low frequency noise & $=0.001$ \\
& Particulates $(5-10 \mu \mathrm{m})$ & $<0.01$ \\
Dry throat & Temperature - diurnal variation & $<0.001$ \\
& Particulates $(10 \mu \mathrm{m})$ & $<0.001$ \\
Headache & Temperature $($ dry bulb) & $<0.01$ \\
& Particulates $(5-10 \mu \mathrm{m})$ & $<0.001$ \\
Lethargy & Multiple noise measures & $<0.001$ \\
\multirow{2}{*}{ Dry skin } & Particulates $(10 \mu \mathrm{m})$ & $<0.01$ \\
\hline
\end{tabular}

*There was instability of the regression model with interaction between variables that could not be controlled. Findings of uncertain significance. 
ures, as first identified in the univariate analysis and identified in several of the buildings independently, are both related to symptoms. Increased particulate counts and particularly the larger particle sizes, were strongly related to itchy eyes, dry throat, headache, and lethargy. For the other symptoms, positive relations were identified, but significance did not reach the 0.01 level set for the study. Noise relations were complex, but overall it supported the individual building analysis in showing a direct effect of increased low frequency noise and a protective effect of increased measures of high frequency noise.

\section{Conclusions}

This study represents a novel approach to investigating the role of environmental variables in the aetiology of sick building syndrome. Also the study is unusual in investigating potentially good quality buildings with few symptoms of the sick building syndrome. The cluster analysis design has limitations as well as advantages. The number of people included in the final analysis was limited to those close to an environmental assessment. However, it would not have been practically possible to measure the exposure of each environmental variable for every member of the building population. Concentrating on hot and cold clusters increased the power of the study to identify positive associations with a limited number of environmental assessments.

The influence of possible confounding factors such as age, sex, and psychosocial (work status) was not accounted for before the analysis. Previous studies of sick building syndrome have shown that younger women with lower work status (secretarial or clerical) are more likely to complain of sick building symptoms. However, none of these studies has determined whether this is directly related to their work status and sex or an indirect effect of the poorer environmental conditions (work overcrowding, least favourable aspect, etc). Controlling for these factors may have lost positive interactions between reported symptoms and environmental measurement by inference.

This study was initially performed to find whether in state of the art air conditioned buildings, there remained a relation between environmental conditions and the symptoms of the sick building syndrome. To interpret the findings a naturally ventilated and known sick building was included in the study. The good design and maintenance features of buildings $A$ and $B$ resulted in both reduced reported symptoms and quality environmental performance (the details of this will be reported separately). These buildings were associated with a lower prevalence of symptoms than the naturally ventilated building for all symptoms except dry throat and headache.

Building $\mathrm{C}$, which was in design terms expected to perform as well as building $\mathrm{A}$ and $\mathrm{B}$, did not achieve this. The environmental study showed that it performed less well for measures of thermal comfort, carbon dioxide concentrations, and particulate counts. The findings were hampered as the building had undergone maintenance between the symptom study and the environmental study, which was against the specifically speculated study protocol. The reason for this unscheduled maintenance was unclear. The interference may have influenced the identified relations, and the results in this building have to be interpreted with caution. The naturally ventilated building generally ranked after buildings $\mathrm{A}$ and $\mathrm{B}$ for symptoms. Despite this as with other similar studies it compared unfavourably with all buildings in certain aspects of environmental control. Particulate concentrations were relatively high, a fact shown in previous studies comparing naturally ventilated with air conditioned buildings. ${ }^{8}$ Also, high concentrations of carbon dioxide were identified indicating relatively low air exchange. However, air velocities were higher than in any of the air conditioned buildings, suggesting local turbulence.

The building with a known history of sick building syndrome experienced high levels of symptoms and poor environmental control. Particulate concentrations and low frequency noise in this building exceeded that in buildings $\mathrm{A}$ and $\mathrm{B}$ considerably and certain measures of thermal comfort were less well controlled. These findings were reflected in prevalence of symptoms and the high number of positive relations identified between environmental variables and symptoms.

In terms of aetiological factors responsible for the development of symptoms, even in the state of the art buildings a few factors could still be identified as having strong associations. However, the factors seem to vary, specifically for each building, and cannot be related to an absolute measure of one or other variable as a general rule across all buildings. Indeed, it may be wise in future to avoid large scale epidemiological studies across many buildings, as pooling data for analysis significantly changes the results and will probably cause a loss of data rather than increased information.

Despite this, it is clear that well designed and air conditioned buildings can out perform the normally used control or naturally ventilated environment. Even in these healthy buildings there may still be environmental factors which are responsible for symptoms and dissatisfaction with the working environment.

There are important negative findings within this study. For example, volatile organic compounds, positive or negative ions, carbon monoxide concentrations, formaldehyde concentrations, and lighting measurements were predominantly irrelevant in the univariate analysis and regression models.

Two consistently positive findings were present throughout the study. Firstly, measures of airborne particulates were strongly associated with all symptoms in the univariate analysis and were found for many of the symptoms on multiple regression analysis. This is consistent with the findings of the Danish Town Hall study, ${ }^{1}$ which although not measuring airborne concentrations of dust in the detail of this study, suggested that fleece factors and shelf factors (possible surrogates for dust concentra- 
tions) were strongly associated with symptoms. An intervention study with cleaning of carpets to remove dust contamination was associated with a significant improvement in reported symptoms. ${ }^{13}$

Secondly, noise has a profound effect on all symptoms. The trend overall was for low frequency sound to be directly associated with symptoms, whereas higher frequency sound seemed to be protective. Experimental studies have shown that exposure to low frequency noise is associated with a deleterious effect on work performance as well as increased irritability and lowered self perception of contentedness. ${ }^{14}$ To fit this into the model of symptoms in sick building syndrome, it might be speculated that noise is acting as a sensitiser and making people more irritable and aware of any dissatisfaction with their working environment. Recent experimental work has suggested that lowering noise levels may reduce symptoms experienced and improve work output. ${ }^{15}$

Both the effects of particulates and low frequency noise are worthy of further investigation. Specifically, this should focus on the constituents of office particulates and the role of noise of different qualities on humans in office environments.

In conclusion, this study has shown consistent relations between dust particulates and noise to symptoms compatible with the sick building syndrome. Other factors are inconsistently associated and vary between buildings. The study has shown that air conditioned buildings can provide a healthy and comfortable environment and that this can be significantly better than that provided by a naturally ventilated building, providing it has been well designed and maintained.
1 Skov $\mathrm{P}$, Valbjorn $\mathrm{O}$, et al. The sick building syndrome in the office environment; the Danish town hall study. Environ Int 1987;13:339-50.

2 Menzres D, Tamblyn RM, Nunes F, et al. Exposure to varying levels of contaminants and symptoms among workers in two office buildings. Am F Public Health 1996;86:1629-33.

3 Woods JE. An engineering approach to controlling indoor air quality. Environ Health Perspect 1991;95:15-21.

4 Bachmann MO, Myers JE. Influences on sick building syndrome in three buildings. Soc Sci Med 1995;40:245-51.

5 Burton DJ. Inadequate air distribution and poor mixing cause IAQ problems. Moving partitions, walls and furniture may change the air flow, often for the worse. Occup Health Saf 1996;65:20-1.

6 Jaakola JJ, Meittnen P. Ventilation rate in office buildings and sick building syndrome. Occup Environ Med 1995;52: $709-14$

7 Hodgson MJ, Frohliger J, Permar E, et al. Symptoms and microenvironmental measures in non-problem buildings. $\mathcal{f}$ Occup Med 1991;33:527-33.

8 Harrison J, Pickering CAC, Fargher EB, et al. An investigation of the relationship between microbial and particulate indoor air pollution and the sick building syndrome. Respir Med 1992;86:225-35.

9 Dietert RR, Hedge A. Toxicological considerations in evaluating indoor air quality and human health; impact of new carpet emissions. Crit Rev Toxicol 1996;26:633-707.

10 Teeuw KB, Vandenbroucke-Grauls CM, Verhoef J. Airborne gram negative bacteria and endotoxin in sick building syndrome. A study of Dutch governmental office buildings. Arch Intern Med 1994;154:2339-45.

11 Nordstrom K, Norback D, Akselsson R. Influence of indoor air quality and personal factors on the sick building syndrome (SBS) in Swedish geriatric hospitals. Occup Environ Med 1995;52:170-6.

12 Abbritti G, Muzi G, Accattoli MP, et al. High prevalence of sick building syndrome in a new air-conditioned building in Italy. Arch Environ Health 1992;47:16-22.

13 Leinster P, Raw G, Thomason N, et al. A modular longitudinal approach to the investigation of sick building syndrome. In: Proceedings of the 5th International Conference on Indoor Air Quality and Climate. Indoor air 90. Vol 2. Toronto: Organising Committee of the 5th International Conference on Indoor Air Quality and Climate, 1990:287-

14 Persson Waye K, Rylander R, Benton S, et al. Effects on performance and work quality due to low frequency ventilation noise. Fournal of Sound Vibration 1997;205:46774.

15 Alm O, Witterseh T, Clausen G, et al. The impact on human perception of simultaneous exposure to thermal load, low frequency ventilation noise and indoor air pollution. In: Proceedings of Indoor Air 99. Edinburgh: BRE 1999;5: 270-5.

\section{Rejected manuscripts}

Authors whose submitted articles are rejected will be advised of the decision and one copy of the article, together with any reviewer's comments, will be returned to them. The
Fournal will destroy remaining copies of the article but correspondence and reviewers' comments will be kept. 